\title{
Evolution of the composition and structure of cleaved and heat-treated icosahedral Al-Pd-Mn quasicrystal surfaces
}

\author{
Ph. Ebert, F. Kluge, B. Grushko, and K. Urban \\ Institut für Festkörperforschung, Forschungszentrum Jülich GmbH, D-52425 Jülich, Germany
}

(Received 16 November 1998; revised manuscript received 1 February 1999)

\begin{abstract}
We investigated the changes in composition and structure induced by heat treatment of cleaved fivefold icosahedral Al-Pd-Mn quasicrystal surfaces by scanning electron microscopy and calibrated Auger electron spectroscopy. With increasing temperature we observed five different composition ranges of the surface coupled with distinct changes in the surface morphology. The changes in composition can be explained by successive evaporation and diffusion processes occurring with increasing temperatures. First, Mn evaporates from the uppermost surface layer, then $\mathrm{Al}$ evaporation starts and induces a further $\mathrm{Mn}$ evaporation leading to an enrichment in Pd. The enrichment is reduced by Mn diffusion from the bulk, Al diffusion from the bulk, and probably simultaneously occurring Pd desorption. Finally, a recrystallization of the surface is induced by the full diffusive mobility of all elements and preferential evaporation of $\mathrm{Mn}$ and to a lesser degree of Al. We also discuss the signature of the bonding configuration of $\mathrm{Al}$ in the Auger spectra of all investigated compositions.
\end{abstract} [S0163-1829(99)02925-2]

\section{INTRODUCTION}

Quasicrystal surfaces attracted considerable attention recently. ${ }^{1}$ On the one hand, the structure of the quasicrystal surfaces is a very debated topic. On the other hand, quasicrystals exhibit very intriguing frictional properties and a significantly increased hardness compared to typical Al alloys, making quasicrystal coatings interesting for applications. For the investigation of the physical properties of quasicrystal surfaces it is necessary to obtain clean surfaces. Three approaches have been realized for the fivefold surface of the icosahedral Al-Pd-Mn quasicrystal. First, the surface can be mechanically polished in air, cleaned by sputtering with noble gas atoms, and then annealed to remove the damage left by sputtering. ${ }^{2-12}$ During this procedure significant changes in the chemical composition occur due to segregation, evaporation, and preferential sputtering. ${ }^{6-12}$ In the second approach, the surfaces are cleaned by thermal evaporation of the oxide layer at very high temperatures. ${ }^{13}$ But again, segregation and evaporation modify the chemical composition. The third approach is the cleavage fracture of quasicrystals in ultrahigh vacuum. ${ }^{14-16}$ In the latter case, the chemically disruptive steps are avoided, but the surface has no chance to equilibrate via diffusion. All these works were driven by the basic question of whether the surface of the quasicrystal maintains in its equilibrium state the bulk stoichiometry and structure, or whether these are changed by the different surface treatments.

In many studies the surface compositions after different treatments of quasicrystals, primarily of $\mathrm{Al}-\mathrm{Pd}-\mathrm{Mn}$ and $\mathrm{Al}-$ $\mathrm{Cu}-\mathrm{Fe}$, have been determined. ${ }^{2-12,16,17}$ All these studies, with exception of Ref. 16, report the composition of sputterannealed surfaces measured by Auger electron spectroscopy (AES) and by (x-ray) photoelectron spectroscopy (XPS). Most of these studies are semiquantitative and are thus only suitable to demonstrate the trends in the development of the surface composition, because the sensitivity factors for the different elements were not calibrated. Indeed, Rouxel et al. showed that the sensitivity factor for Fe differs considerably compared to the values in the standard tabulations. ${ }^{17}$ For the sputter-annealed surfaces of the icosahedral Al-Pd-Mn quasicrystal the uncalibrated composition measurements yield, in general, a depletion of the surface in Mn after heat treatment. So far no calibrated measurements have been carried out.

In this paper we present the calibrated composition measurement of the cleaved fivefold surface of the icosahedral Al-Pd-Mn quasicrystal using Auger electron spectroscopy and complementary scanning electron microscopy (SEM). We observe several changes in composition accompanied by changes in the surface morphology with increasing temperature up to the melting of the samples. The results enable us to determine the effects of evaporation and diffusion of each element separately, as well as to detect the effect of surface phase transformations on the surface structure and composition.

\section{EXPERIMENT}

For the experiments we used samples $\left(3 \times 3 \times 7 \mathrm{~mm}^{3}\right)$ cut from two different Czochralski-grown $\mathrm{Al}_{70.5} \mathrm{Pd}_{21} \mathrm{Mn}_{8.5}$ single quasicrystals. The average composition of the quasicrystals was determined by inductively coupled plasma optical emission spectroscopy (ICPOES). Two cleavage slots were cut by spark erosion into each sample perpendicular to the long axis of the samples, which is parallel to the fivefold axis. Thus we study the fivefold cleavage surface. Some of the samples were annealed for $65 \mathrm{~h}$ at $820^{\circ} \mathrm{C}$ in an argon flow furnace before further processing. After transferring the samples into the vacuum chamber they were outgassed in ultrahigh vacuum for several hours at temperatures ranging from 350 to $500{ }^{\circ} \mathrm{C}$ before cleavage. The samples were cleaved using a double-wedge technique at pressures of $3 \times 10^{-9}$ to 1 $\times 10^{-8} \mathrm{~Pa}$ at room temperature. During heat treatment of the samples up to $300{ }^{\circ} \mathrm{C}$ the pressure remained below 1 
$\times 10^{-8} \mathrm{~Pa}$. With increasing temperature the maximum pressure gradually increased and remained usually in the low $10^{-7}-\mathrm{Pa}$ range. After heat treatment the pressure quickly reached the low $10^{-8}$ - (or even high $10^{-9}$-) Pa range and the samples were immediately investigated by AES. Each heating cycle lasted $1 \mathrm{~h}$ with exception of the highest temperature $(20 \mathrm{~min})$. The samples were subjected to three to five consecutive heating cycles with increasing temperature. The heating was achieved by indirect radiation heating of the whole sample holder from the back side using a tungsten filament. Only for the highest temperature an electron-beam heating of the back side of the sample holder was applied. Neither the sample nor any temperature measurement spots were directly heated by electron irradiation, only indirectly by heat conductivity and heat radiation from the sample holder. Between each heat treatment the surface was investigated by AES, SEM, and light-optical microscopy. After the final measurement the samples were investigated ex situ by scanning electron microscopy to monitor the surface morphology after the different heating steps at the different surface areas investigated previously with the highest possible resolution.

The Auger electron spectroscopy data were acquired using a Varian cylindrical mirror analyzer with an incorporated electron beam. The scannable electron beam had a focus of about $25 \mu \mathrm{m}$ in diameter. Each data point refers to the average composition within an area determined by the spot size. In addition, secondary electrons were used to image the surface by scanning electron microscopy in situ in order to position the electron beam. We applied a beam energy of 3.00 $\mathrm{keV}$ and a beam current of $0.8-2 \mu \mathrm{A}$. The calibration of the Auger system geometry was performed at 1.90 or $2.00 \mathrm{keV}$ using the elastic peak. The calibration was checked in the whole energy range of interest (i.e., $0.30-2.00 \mathrm{keV}$ ). The spectra were acquired using the lock-in technique. The compositions were then deduced from the differentiated spectra as described in Ref. 21. The sensitivity factors were calibrated using the spectra obtained at room temperature directly after cleavage and the chemical composition determined from the ICPOES measurements. The calibrated sensitivity factors were applied to all data points.

The temperatures were measured up to $350{ }^{\circ} \mathrm{C}$ on a spot on the sample holder directly adjacent to the sample using a phosphorescence-decay-based absolute measurement technique manufactured by Luxtron. We also calibrated the temperature difference between the temperature measured on the sample holder and that of the sample by applying exactly the same measurement spots on the calibration sample and the sample holder. All calibration samples yielded the same temperature differences as a function of temperature. Above $350{ }^{\circ} \mathrm{C}$ the temperature is determined optically by an infrared pyrometer, which has been calibrated by comparing the temperatures acquired on the sample holder on a graphite spot (and on the adjacent stainless steel) with the temperatures measured on a graphite calibration sample. In addition, we calibrated the system with the absolute measurement technique of Luxtron. The temperatures were also measured directly on the sample, i.e., on the cleaved surface and on the cleavage slots, which were rough by spark erosion and exhibited an emission coefficient close to that of graphite. All
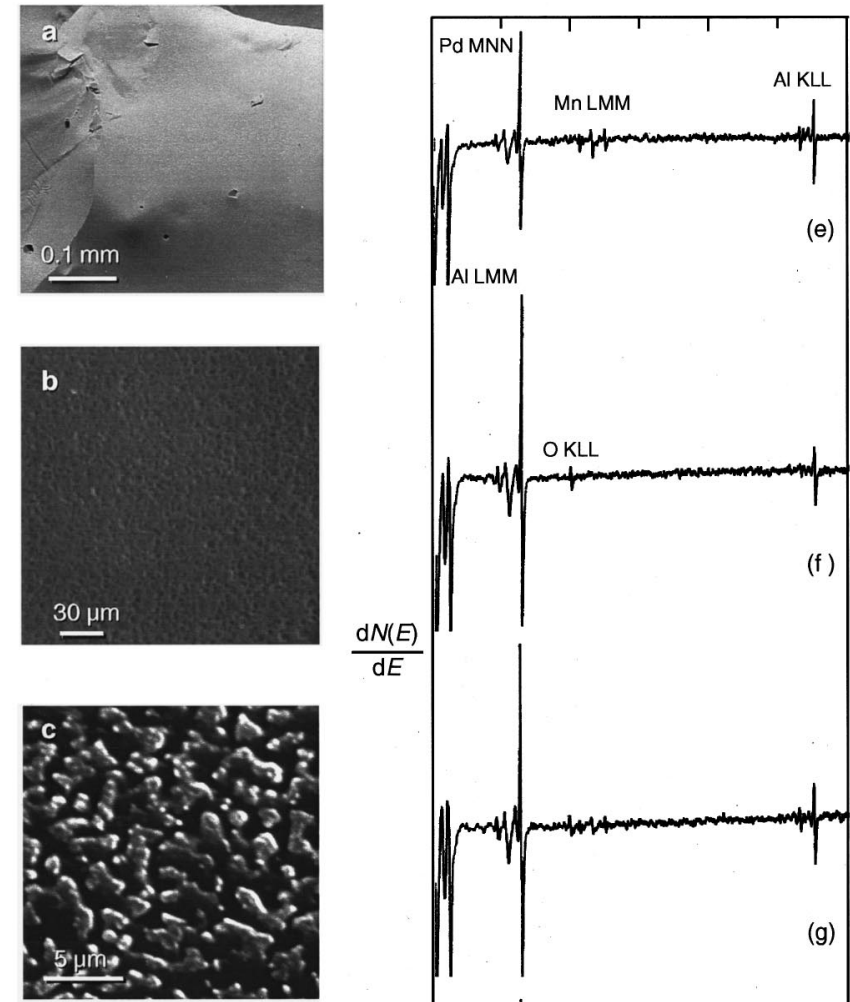

AI LMM

(e)
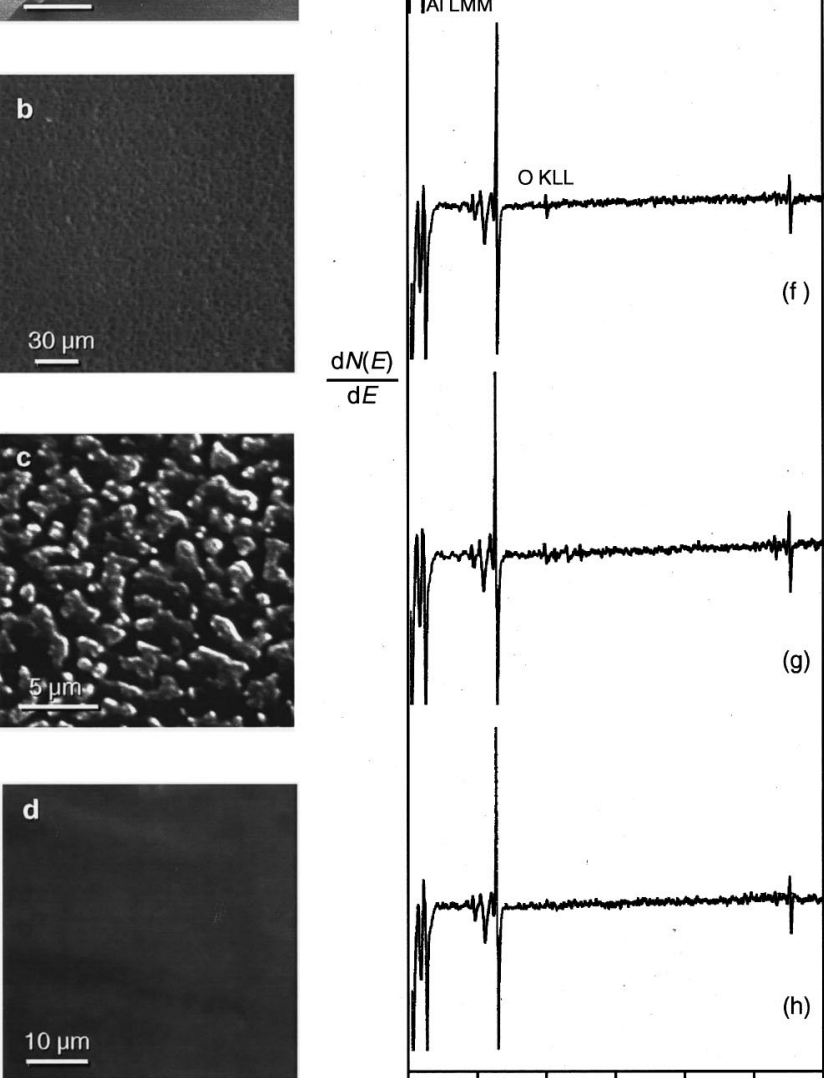

(f)

FIG. 1. Scanning electron microscopy images of the cleaved fivefold Al-Pd-Mn quasicrystal surface (a) at room temperature, (b) after a heat treatment at $420{ }^{\circ} \mathrm{C}$, (c) $590{ }^{\circ} \mathrm{C}$, and (d) $750{ }^{\circ} \mathrm{C}$ with the corresponding Auger spectra taken (e) at room temperature, (f) after heat treatment at a temperature of $400{ }^{\circ} \mathrm{C},(\mathrm{g}) 560{ }^{\circ} \mathrm{C}$, and $(\mathrm{h})$ $750{ }^{\circ} \mathrm{C}$. The $\mathrm{Al} L M M$ peak at $68 \mathrm{eV}$ is partly cut off in the spectra. The Pd $M N N$, Mn $L M M$, and Al KLL peaks were used for the quantification of the composition shown in Fig. 2. The intensity of the spectra is shown in arbitrary units.

these measurements allowed us to determine accurately the temperature within the error bars given below.

\section{EXPERIMENTAL RESULTS}

Figures 1(a)-1(d) show on the left-hand side the surface structure as observed in scanning electron microscopy after cleavage and subsequent heating cycles. On the right-hand side [Figs. 1(e)-1(h)] are overview Auger spectra obtained at temperatures comparable to those of the respective SEM images. After cleavage at room temperature the surface has a metallic optical reflectivity and consists of large flat areas. In SEM images no features can be resolved on the cleaved surfaces. Only in scanning-tunneling-microscopy images a cluster-based surface structure with a roughness of about 2 
$\mathrm{nm}$ is observed. ${ }^{14}$ On these surfaces we observed Auger spectra as the one shown in Fig. 1(e). Clearly the group of Pd peaks with the highest one at $330 \mathrm{eV}$, the three Mn peaks (at 542,589 , and $636 \mathrm{eV}$ ), and the group of $\mathrm{Al}$ peaks with the largest one at $1396 \mathrm{eV}$ can be recognized. In addition one can observe the Al LMM peak at $68 \mathrm{eV}$ and a Mn-related peak at nominally $40 \mathrm{eV}$. No other peaks occur, in particular, no oxygen- or carbon-related features. This demonstrates that the cleavage surface is free of any contaminants. With increasing temperature the surface loses at about $350{ }^{\circ} \mathrm{C}$ its metallic reflectivity, due to the formation of small irregularly shaped holes. Figure 1(b) shows a SEM image of such a surface. The surface has a light-matte appearance at this stage. The corresponding Auger spectra [Fig. 1(f)] exhibit only very small Mn peaks, an increased Pd peak, and a decreased $\mathrm{Al}$ peak. With further heating to temperatures in the range of $550-590{ }^{\circ} \mathrm{C}$ the Mn peaks reappear [Fig. $1(\mathrm{~g})$ ], but the surface becomes significantly rougher [Fig. 1(c)] and is fully matted. Finally at $750{ }^{\circ} \mathrm{C}$ the surface undergoes a major change. It regains its metallic reflectivity [Fig. 1(d)] and loses most of the Mn. At $750{ }^{\circ} \mathrm{C}$ we also observed that the oxidized material present on the cleavage slots and the outside faces of the sample migrates onto the cleavage surface slowly. At even higher temperatures (about $790^{\circ} \mathrm{C}$ ) oxidized materials cover within minutes most of the cleavage surface starting from the side facing the cleavage slots. In addition, a clear surface melting is observed. We limited our experiments to the temperatures where still a wide clean surface is present.

From Auger spectra, such as those shown in Fig. 1, and others with higher magnification we deduced the concentrations. For doing so we had to calibrate the sensitivity factors for the three elements using the Auger spectra obtained directly after cleavage and the composition data of each sample. This procedure assumes that no diffusion takes place at room temperature. The data presented below support this assumption. The sensitivity factors with respect to the sensitivity factor of $\mathrm{Pd}\left(S_{\mathrm{Pd}}\right)$ of 0.8 are for $\mathrm{Al}\left(S_{\mathrm{Al}}\right) 0.088$ \pm 0.009 and for $\mathrm{Mn}\left(S_{\mathrm{Mn}}\right) \quad 0.25 \pm 0.02$ (average of all samples, the error margins give reproducibility of the sensitivity factor from sample to sample). Thus we found for our system a higher sensitivity factor for Al than in Ref. 21. Using the calibrated sensitivity factors $S_{i}$ we calculated the concentrations $c_{i}$ of all three elements using the relation $c_{i}$ $=\left(h_{i} / S_{i}\right)\left(\Sigma h_{j} / S_{j}\right)^{-1}$, with $h_{i}$ being the peak-to-peak heights of the highest Pd (MNN, $330 \mathrm{eV}$ ), Mn (LMM, 589 $\mathrm{eV}$ ), and $\mathrm{Al}(\mathrm{KLL}, 1396 \mathrm{eV})$ peaks in the differentiated Auger spectra. These peaks are marked in the spectra in Fig. 1.

Figure 2(a) shows the composition values determined on the surface as a function of the temperature. Significant changes in composition can be observed above $350^{\circ} \mathrm{C}$. A close look at Fig. 2(b) shows, however, that the Mn concentration drops already between 100 and $180^{\circ} \mathrm{C}$ by about $1 \%$. The $\mathrm{Al}$ concentration increases by about the same amount. At $350{ }^{\circ} \mathrm{C}$ the $\mathrm{Mn}$ concentration decreases further, while the $\mathrm{Al}$ and $\mathrm{Pd}$ concentrations decrease and increase by $10-15 \%$, respectively. At $550-590^{\circ} \mathrm{C}$ the surface regained nearly the bulk starting compositions observed directly after cleavage, i.e., the $\mathrm{Mn}$ and $\mathrm{Al}$ concentrations had increased and the Pd concentration decreased. The increase of the $\mathrm{Mn}$ concentration starts at a temperature about $100{ }^{\circ} \mathrm{C}$ lower than that
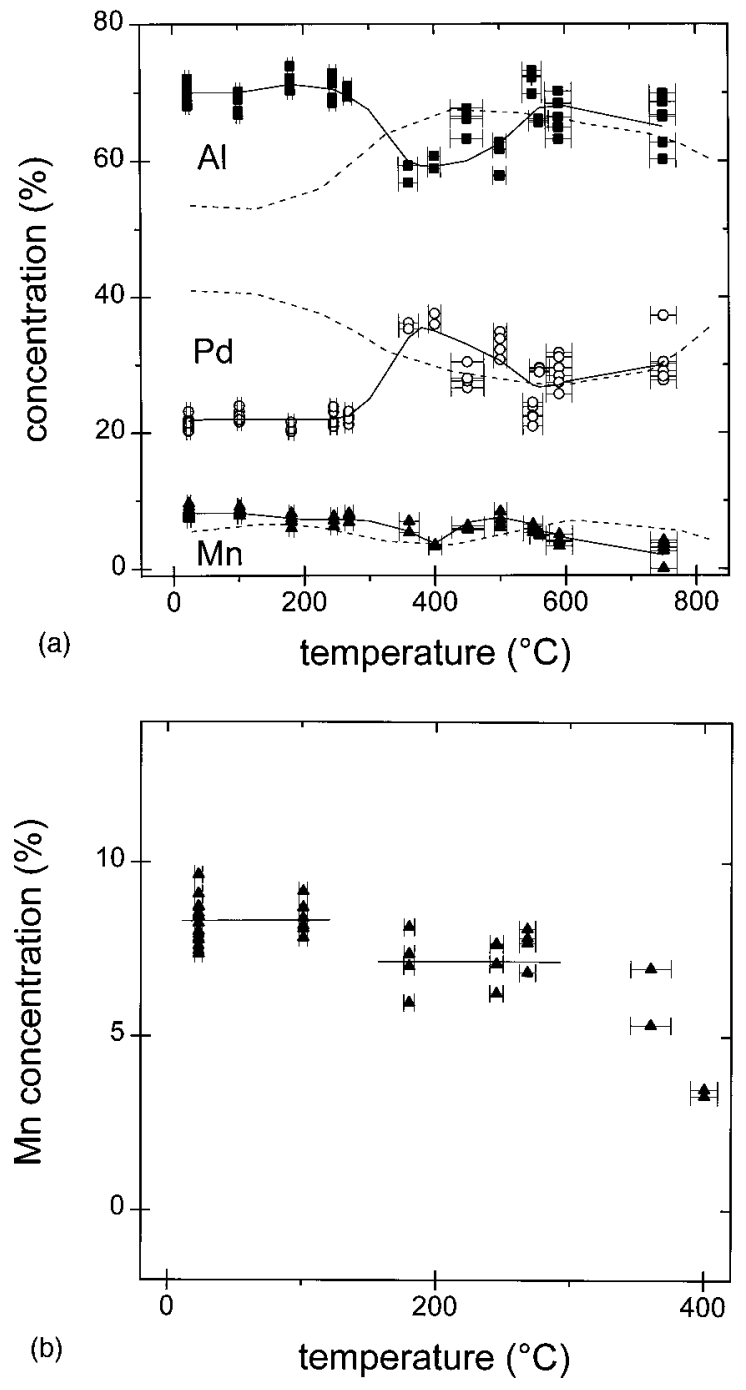

FIG. 2. (a) Composition of the surface as a function of the temperature. Frame (b) shows magnified the evolution of the Mn concentration. The solid lines should guide the eye. The dashed lines indicate the compositions found on sputtered surfaces as a function of the temperature from Ref. 6 .

where the $\mathrm{Al}$ concentration increases. Above $550{ }^{\circ} \mathrm{C}$ the $\mathrm{Mn}$ concentration decreases again. At $750^{\circ} \mathrm{C}$ we observed several surface areas with no $\mathrm{Mn}$ at all and the overall $\mathrm{Mn}$ concentration is between $2 \%$ and $4 \%$ only. The surface is essentially a Pd-Al alloy with $60-70 \%$ Al.

At room temperature the composition values of different areas on several samples do not scatter very much. Most values are within a $\pm 2 \%$ range. With increasing temperature we observed an increasing scattering of the values to about $\pm 5 \%$. This indicates that the surface composition is increasingly inhomogeneous at higher temperatures. However, we observed the same changes in composition for all four samples investigated, independent of the specific crystal the samples were cut from or the homogenitization heat treatment at $820^{\circ} \mathrm{C}$ for $65 \mathrm{~h}$ preceding the cleavage.

Figure 3 shows the measured composition values in a ternary composition diagram as a function of the temperature. Composition values for different temperatures are shown with different symbols. The triangles show the data obtained at room temperature. In Fig. 3(a) the observed range of com- 


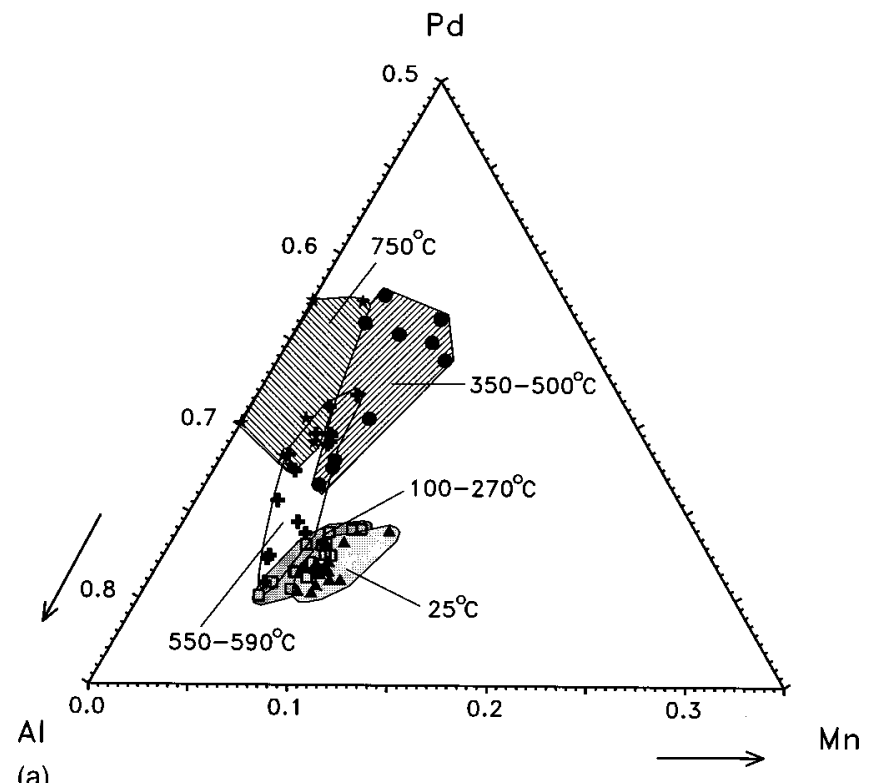

(a)

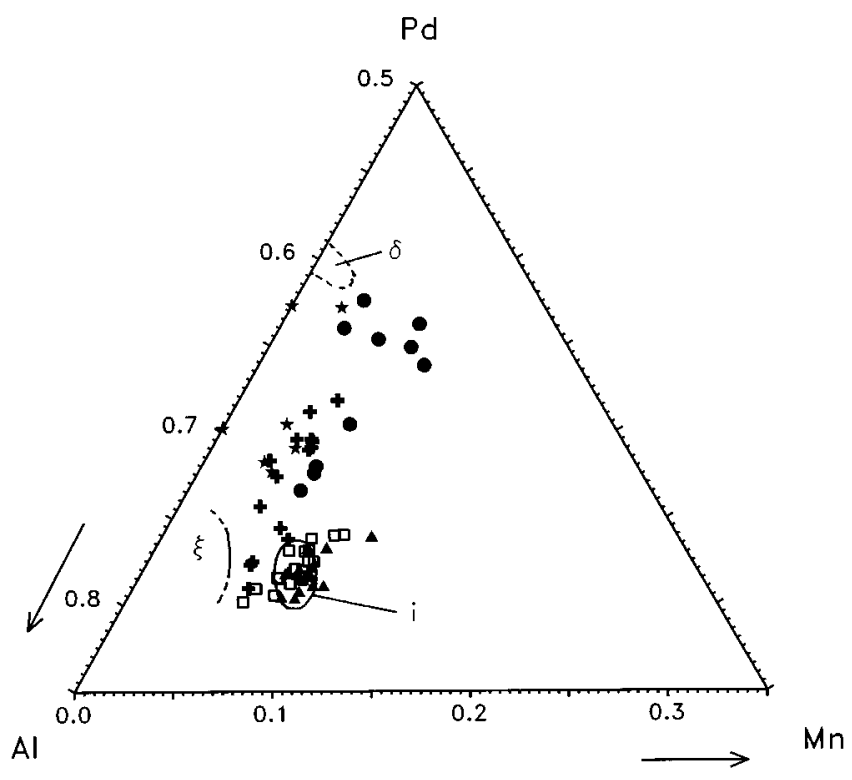

(b)

FIG. 3. Measured composition values shown in a ternary composition diagram. The observed compositions of different temperature ranges are grouped with different symbols $(\boldsymbol{\Lambda}$, room temperature; $\square, 100-270{ }^{\circ} \mathrm{C} ; 0,350-500{ }^{\circ} \mathrm{C},+, 550-590{ }^{\circ} \mathrm{C}$, and $\star$, $750{ }^{\circ} \mathrm{C}$ ). In frame (a) the composition areas of the surface are shown as striped areas for the different temperature ranges to give an indication of the extension ranges of the surface compositions. In frame (b) the composition ranges of the bulk icosahedral (i), $\delta$, and $\xi$ phases are indicated, too.

positions at room temperature is indicated as dotted area (with triangles). With increasing temperature $\left(180-270{ }^{\circ} \mathrm{C}\right.$ ) the composition range drifts slightly toward lower Mn concentrations (open squares). With further increase to temperatures in the range of $350-500{ }^{\circ} \mathrm{C}$ the composition range is strongly shifted to a Pd-enriched and slightly Mn-depleted area. A further increase in temperature $\left(550-590{ }^{\circ} \mathrm{C}\right)$ drives the composition nearly back to the initial starting composition (with a larger scattering, however), although it is still somewhat $\mathrm{Mn}$ depleted and $\mathrm{Pd}$ enriched. At $750^{\circ} \mathrm{C}$, finally,

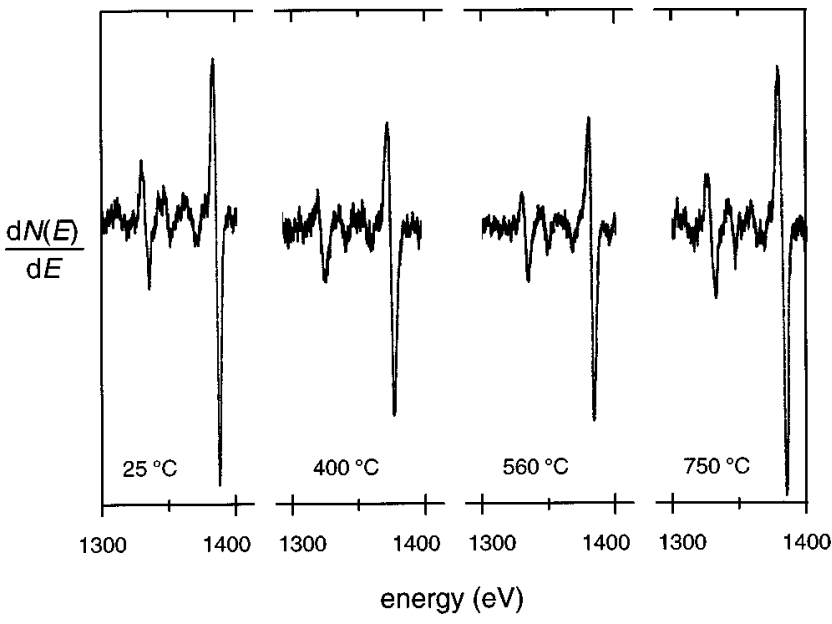

FIG. 4. The group of $\mathrm{Al}$ peaks in the Auger spectra between 1300 and $1400 \mathrm{eV}$ for different temperatures indicated below each spectra. The intensities are shown in arbitrary units.

the composition range is shifted again strongly into Pd-rich areas with very little Mn. Figure 3(b) shows that most of the compositions observed on the surface at room temperature overlap well the single phase region of the bulk icosahedral phase at $790{ }^{\circ} \mathrm{C} .{ }^{18}$ At $750{ }^{\circ} \mathrm{C}$ the surface composition corresponds to compositions in the bulk, which exhibit a mixture of the $\xi$ (orthorhombic approximant phase of the icosahedral Al-Pd-Mn quasicrystal ${ }^{19,20}$ ) and $\delta$ phases.

Most of the composition values were measured directly after the heat treatment. We, however, also measured the composition values some time later again and found that changes occurred after annealing to $500{ }^{\circ} \mathrm{C}$. Two days after radiation cooling the $\mathrm{Al}$ concentrations increased by about $4 \%$, Pd decreased by about $3 \%$, and Mn decreased by about $1 \%$, compared to the composition found directly after the heating. This drives the concentration somewhat toward the composition observed at $550-590{ }^{\circ} \mathrm{C}$. In contrast, no statistically significant changes were observed 4 days after annealing at $590^{\circ} \mathrm{C}$.

The spectra in Figs. 1(f) and $1(\mathrm{~g})$ both exhibit a small amount of oxygen (peak at $503 \mathrm{eV}$ marked $\mathrm{O} K L L$ ). The oxygen arises from a prolonged $e$-beam irradiation (of the Auger measurements) and its concentration increased with increasing irradiation time. No oxygen has been found after cleavage and if the samples were strongly outgassed. We found that subsequent heat treatments reduced the oxygen concentration by typically $50 \%$. After heating to $750{ }^{\circ} \mathrm{C}$ no oxygen was detectable.

The different peak positions agree within the measurement accuracy well with the literature data of Ref. 21. We nevertheless focus in Fig. 4 on the group of Al peaks, as they exhibit a very distinct shape. The group consists of four peaks. The peak with the lowest energy is typically twice as intensive as the rather small second and third peaks. The fourth peak is the most intensive one. At energies smaller than that of the first peak we could not reproduce statistically any further peak. This shape of the group of peaks differs considerably from that expected for pure $\mathrm{Al}$ metal, i.e., a cascade of five peaks exhibiting an increasing intensity with increasing energy. ${ }^{21}$ The observed shape rather has some similarities with the $\mathrm{Al}$ peak found in $\mathrm{Al}_{2} \mathrm{O}_{3}$. Figure 4 also 
shows that the Al peak structure does not change with temperature, i.e., in all the different compositions and surface phases observed.

\section{DISCUSSION}

The measured concentration values indicate several changes in the surface composition. These are (i) a decrease of the $\mathrm{Mn}$ concentration from $8.5 \%$ to about $7.5 \%$ between 100 and $180^{\circ} \mathrm{C}$, (ii) a strong decrease of the $\mathrm{Al}$ concentration and a corresponding increase of the Pd concentration at $350{ }^{\circ} \mathrm{C}$, (iii) a further decrease of the $\mathrm{Mn}$ concentration reaching its lowest value at $400{ }^{\circ} \mathrm{C}$, (iv) an increase of the Mn concentration from 400 to $500{ }^{\circ} \mathrm{C}$, (v) an increase of the $\mathrm{Al}$ concentration and a corresponding decrease of the $\mathrm{Pd}$ concentration toward $550-590^{\circ} \mathrm{C}$, and finally, (vi) the formation of an Al-Pd alloy, which has only a little Mn incorporated. These changes in composition are accompanied by distinct changes of the surface morphology: the surface changes from smooth surface with metallic optical reflectivity, via a rough surface morphology with increasing roughness that induces the matte appearance, to a smooth surface structure having a metallic optical reflectivity again.

In order to explain the observed changes we have to consider evaporation and diffusion of the different elements of the alloy and a possible melting-inducing reordering and recrystallization. It is well known that $\mathrm{Pd}$ has the lowest vapor pressure and Mn the highest one. ${ }^{22}$ Thus one should expect that if desorption occurs, the Mn concentration should decrease first. Indeed, between 100 and $180^{\circ} \mathrm{C}$ [point (i) above] we observe a first decrease of the Mn concentration. However, the Mn concentration does not decrease continuously as expected for continuing desorption. It rather decreases only a little and then reaches a new plateau. This initial decrease of the Mn concentration does not change the surface structure in any detectable way in SEM images. We were unable to detect a change of the surface structure in scanning tunneling microscopy images. ${ }^{15}$ This suggests that only the $\mathrm{Mn}$ in the topmost surface layer evaporates without inducing significant changes of the cluster structure, because essentially no changes were observed in STM images. ${ }^{15}$ This conclusion is also supported by the Mn diffusion data. ${ }^{23} \mathrm{Mn}$-tracer diffusion experiments in Al-Pd-Mn yield a diffusion coefficient of $D_{\mathrm{Mn}}(T)=1.2 \times 10^{-4} \times \exp (-1.99 \mathrm{eV} / k T)$. With the wellknown bulk relation of the distance reached by diffusion $r$ $=(6 D t)^{1 / 2}$ within a time interval $t$, one obtains a distance of $0.016 \mathrm{~nm} / \mathrm{h}$ for $\mathrm{Mn}$ at $180^{\circ} \mathrm{C}$. Thus an inward diffusion of $\mathrm{Mn}$ into the bulk can be excluded at this temperature. In case Mn exhibits at low temperatures a phason-assisted diffusion as suggested by Ref. 24, we underestimated somewhat the diffusion distance, but essentially our conclusions will not be changed much, because we see a clear onset of Mn diffusion as discribed below at higher temperatures and because the diffusion distance is so small that even an underestimation by a factor of 100 does not change the conclusion. This note about the estimation of diffusion distances applies to the discussion below, too. Thus due to the lack of any diffusion, only atoms from the topmost surface layer can evaporate. We note that the Auger signal yields a depth-weighted average composition of a surface layer about $0.8-2 \mathrm{~nm}$ thick, depending on the electron energy. Thus if the uppermost layer is completely $\mathrm{Mn}$ depleted we still detect $\mathrm{Mn}$ in lower atomic layers.

The equilibrium vapor-pressure data ${ }^{22}$ show that the vapor pressure of $\mathrm{Al}$ reaches equal values to that of Mn typically at temperatures about $120^{\circ} \mathrm{C}$ higher than those of Mn. Thus if Mn desorption starts at $180^{\circ} \mathrm{C}$ one can expect that $\mathrm{Al} \mathrm{de-}$ sorption should start somewhere above $300^{\circ} \mathrm{C}$. Indeed, we found a strong decrease of the $\mathrm{Al}$ concentration at $350^{\circ} \mathrm{C}$. At this temperature diffusion is still essentially inhibited, because Mn can only reach a distance of $2 \mathrm{~nm}$ in $1 \mathrm{~h}$. Thus the change in composition must be again due to desorption, this time of Al. At this temperature Pd diffusion can also be excluded. The diffusion coefficient ${ }^{24}$ of $D_{\mathrm{Pd}}(T)=1.4$ $\times 10^{-10} \times \exp (-1.2 \mathrm{eV} / k T)$ yields a distance reached by diffusion in $1 \mathrm{~h}$ of only $1.7 \mathrm{~nm}$. The lack of diffusion also explains the very rough surface morphology and the irregularly shaped holes formed. If diffusion would be present well-faceted holes would appear, in contrast to our observation. Thus the increase of the Pd concentration is only the result of preferential $\mathrm{Al}$ desorption with essentially no diffusion.

Above $350{ }^{\circ} \mathrm{C}$ the $\mathrm{Mn}$ concentration decreases further. This step labeled (iii) above can be explained as follows. Due to the formation of many holes at $350{ }^{\circ} \mathrm{C}$ by $\mathrm{Al}$ evaporation, more surface layers are exposed and the $\mathrm{Mn}$ in these layers is able to evaporate. This process continues until effect (iv), an increase of the Mn concentration from 400 to $500{ }^{\circ} \mathrm{C}$ is observed. We interpret the latter as the signature of $\mathrm{Mn}$ diffusion from the bulk to the surface. The diffusion coefficient ${ }^{23}$ shows that $\mathrm{Mn}$ can migrate nearly $1 \mu \mathrm{m} / \mathrm{h}$ at $450{ }^{\circ} \mathrm{C}$. This is largely sufficient to support a significant diffusion of Mn from the bulk to the surface.

We now turn to the increase of the $\mathrm{Al}$ concentration and the corresponding decrease of the Pd concentration at 550$590{ }^{\circ} \mathrm{C}$ [observation (v)]. There are two candidate processes to explain this observation: first, $\mathrm{Al}$ diffusion, and second, $\mathrm{Pd}$ evaporation. Pd diffusion has also to be considered.

So far no diffusion data of $\mathrm{Al}$ in $\mathrm{Al}-\mathrm{Pd}-\mathrm{Mn}$ quasicrystals are known. Taking general properties of $\mathrm{Al}$ and $\mathrm{Pd}$ into account, such as their melting point, one should expect that $\mathrm{Al}$ diffusion is faster than Pd diffusion in Al-Pd-Mn quasicrystals. At $550{ }^{\circ} \mathrm{C}$ diffusion allows Pd to migrate about $70 \mathrm{~nm}$ in $1 \mathrm{~h}^{24}$ If $\mathrm{Al}$ diffusion is faster it should be possible that $\mathrm{Al}$ diffuses from the bulk to the surface. This is supported by the observation of an increase of the $\mathrm{Al}$ concentration over a time period of 2 days after heat treatment at $500^{\circ} \mathrm{C}$. At $590^{\circ} \mathrm{C}$ we did not observe this effect, suggesting that the surface reached a kind of steady state, i.e., diffusion equilibrated the surface composition.

The vapor pressures under Knudsen conditions ${ }^{22}$ show that pure $\mathrm{Pd}$ reaches the same vapor pressure as pure $\mathrm{Al}$ at temperatures about $140^{\circ} \mathrm{C}$ higher that those of $\mathrm{Al}$. If we consider that $\mathrm{Al}$ desorption occurred under our Langmuir conditions at $350{ }^{\circ} \mathrm{C}$, then we can expect that Pd evaporation starts somewhere above $500^{\circ} \mathrm{C}$. This would agree with the observed decrease of the $\mathrm{Pd}$ concentration at $550-590^{\circ} \mathrm{C}$. We therefore suggest that the increased $\mathrm{Al}$ and decreased $\mathrm{Pd}$ concentrations at $550-590{ }^{\circ} \mathrm{C}$ are likely to be the result of $\mathrm{Al}$ diffusion from the bulk and Pd evaporation.

The observed surface morphology also supports the conclusion that diffusion plays a significant role in the increase 
of the $\mathrm{Al}$ concentration at $550-590{ }^{\circ} \mathrm{C}$. We observed on samples annealed in this temperature range well-faceted holes and the scanning tunneling microscopy images revealed atomically flat terraces separated by steps. ${ }^{15}$ Such terraces can only be formed if a substantial diffusive motion is possible.

Finally, the change of the surface structure from rough to smooth and the corresponding modification of the composition observed at $750{ }^{\circ} \mathrm{C}$ demonstrate that diffusive mass transport is at this temperature possible for all elements. Indeed, the diffusion coefficient of $\mathrm{Pd}$ in Al-Pd-Mn quasicrystals ${ }^{24}$ indicates that $\mathrm{Pd}$ can be displaced by nearly $20 \mu \mathrm{m}$ in $1 \mathrm{~h}$. The reduction of the roughness at $750^{\circ} \mathrm{C}$ can be explained by a reduction of the total surface area to minimize the energy of the surface likely to be connected with surface melting. Indeed, the composition observed on the surface corresponds in the Al-Pd phase diagram to a melting temperature of $790{ }^{\circ} \mathrm{C} .{ }^{25}$ Heating the sample to $790{ }^{\circ} \mathrm{C}$ resulted in a clear surface melting coupled with a fast diffusion of oxidized material from the sides of the sample and, in particular, from the cleavage slots over the whole cleavage surface. The melting temperature is known to increase with increasing Mn concentration, but we observed only very low amounts of $\mathrm{Mn}$. The composition found can be understood on the basis of different evaporation rates of the three elements, which favors Pd enrichment and $\mathrm{Mn}$, as well as Al depletion. As shown in Fig. 3(b) we found a final composition that would correspond in the bulk to a mixture of the $\xi$ and $\delta$ phases. ${ }^{19,20}$ In fact, a very similar composition has been found on the inner surfaces of grown-in voids in AlPd-Mn quasicrystals. ${ }^{16}$ Such surfaces have been suggested to be equilibrium surfaces, because they have been in equilibrium with their vapor during growth of the quasicrystal.

At this stage we compare the evolution of the surface structure and composition with that found on sputtered surfaces. The dashed lines in Fig. 2(a) indicate the compositions found by AES after sputtering and annealing as a function of the temperature (redrawn from Ref. 6). The composition found on surfaces sputtered at room temperature is significantly different compared to that found on the cleavage surfaces because of a selective sputtering of the three elements. However, with increasing temperature the compositions on both types of surfaces approach each other and finally overlap. It is noteworthy that the same trends in composition changes are observed above $590^{\circ} \mathrm{C}$. A sputtered-annealed surface has a composition of $\mathrm{Al}_{62} \mathrm{Pd}_{34} \mathrm{Mn}_{4}$ at about $830^{\circ} \mathrm{C}$ (Ref. 8), which is very similar to ours at $750{ }^{\circ} \mathrm{C}$. An XPS study of the composition of the sputtered-annealed surface also shows a formation of essentially an Al-Pd alloy with increased $\mathrm{Pd}$ concentration above $650{ }^{\circ} \mathrm{C} .{ }^{11}$ The results of a full-hemisperical $\mathrm{x}$-ray photoelectron diffraction study show that the surface obtained at $750{ }^{\circ} \mathrm{C}$ after sputtering consists of five domains of a cubic Al-Pd phase with its (110) axis parallel to the fivefold icosahedral axis. ${ }^{26}$

The increase of the $\mathrm{Al}$ concentration with increasing temperature below $400-500{ }^{\circ} \mathrm{C}$ has its analogy on the cleaved surfaces, too. Only the onset temperatures differ slightly, something that may arise from the sputter damage. The increase of the $\mathrm{Al}$ concentration is commonly attributed to $\mathrm{Al}$ diffusion from the bulk toward the surface. This view is also supported by the fact that annealing sputtered Al-Pd-Mn and
$\mathrm{Al}-\mathrm{Cu}-\mathrm{Fe}$ quasicrystal surfaces at $550-600{ }^{\circ} \mathrm{C}$ restores in both cases the composition from the Al-depleted sputtered surface toward the bulk composition. ${ }^{8,27}$ It also induces a phase transformation from a cubic overlayer to a quasicrystaline surface. ${ }^{10,12,27}$

The evolution with temperature of the Mn concentration on the sputtered surface [see Fig. 2(a)] exhibits very similar changes as those observed on the cleaved surface. In particular, a minimum Mn concentration is observed in both cases at $400{ }^{\circ} \mathrm{C}$, an increase from 400 to $500{ }^{\circ} \mathrm{C}$ for the cleaved and $400-600^{\circ} \mathrm{C}$ for the sputtered surface, and a decrease above $600{ }^{\circ} \mathrm{C}$. These changes in composition can be explained essentially with the same model presented above for the cleaved surface.

Finally, we concentrate on the shape of the group of $\mathrm{Al}$ peaks in the Auger spectra. Figure 4 showed that the $\mathrm{Al}$ peaks exhibit distinct height relations and this distinct shape is the same in all the different surface compositions studied. The distinct shape can be observed in the spectra shown in Ref. 16, too. The shape of this group of $\mathrm{Al}$ peaks is somewhat closer to that of $\mathrm{Al}$ in $\mathrm{Al}_{2} \mathrm{O}_{3}$ than that of pure metallic $\mathrm{Al}$. This suggests that the $\mathrm{Al}$ atoms are bonded differently in the quasicrystal than in pure Al. Although the details are extremely difficult to clarify, it is obvious that $\mathrm{Al}$ in $\mathrm{Al}_{2} \mathrm{O}_{3}$ has a nonmetallic bonding coupled with a strong charge transfer, while $\mathrm{Al}$ in pure $\mathrm{Al}$ forms a metallic bonding with no charge transfer. The observed spectra being somewhere in their shape between those of the two Al bonding configurations suggest that the spectra observed on the cleaved surfaces are the signature of a type of bonding between the two configurations. This is in agreement with the explanation that the stability of quasicrystals is enhanced due to a charge transfer from the $\mathrm{Al}$ conduction electrons to the $d$ levels of the transition elements $\mathrm{Mn}$ and $\mathrm{Pd}$. For a detailed understanding it is, however, also necessary to take the HumeRothery mechanisms ${ }^{28}$ and possible modifications of the valence band due to $s p$ - $d$ hybridization effects ${ }^{29}$ into account. In this context it is interesting to note that the shape of the peak remains unchanged for all surface structures and compositions. This suggests that the bonding structure of $\mathrm{Al}$ is similar for all observed surface compositions.

\section{CONCLUSIONS}

We investigated the evolution of the surface structure and composition with temperature of cleaved icosahedral AlPd-Mn quasicrystal surface perpendicular to the fivefold axis using scanning electron microscopy and calibrated Auger electron spectroscopy. We found several changes of composition and structure, which can be explained by different consecutive kinetic effects with temperature. First, we observe a small Mn desorption from the topmost surface layer only, then strong $\mathrm{Al}$ desorption results in further $\mathrm{Mn}$ desorption and $\mathrm{Pd}$ enrichment. This is followed by Mn diffusion and later by $\mathrm{Al}$ diffusion from the bulk to the surface. It is likely that $\mathrm{Pd}$ desorption occurs simultaneously to Al diffusion. The last step occurring at $550-590{ }^{\circ} \mathrm{C}$ restored a composition close to the bulk composition. These desorption and diffu- 
sion steps made the surface structure increasingly rough, but at $750^{\circ} \mathrm{C}$ the surface structure recrystallized fully and a $\mathrm{Mn}$ depleted Al-Pd alloy with no surface roughness is found. The latter step is correlated with full diffusive motion of all elements of the quasicrystal and preferential evaporative loss of $\mathrm{Mn}$ and to a lesser degree $\mathrm{Al}$ compared to $\mathrm{Pd}$. The results obtained for the cleaved surface exhibit significant similarities with the sputtered surfaces.

\section{ACKNOWLEDGMENTS}

The authors thank K. H. Graf for indefatigable technical support and many helpful discussions, D. Naumovic, C. J. Jenks, and K. Horn for stimulating discussions, D. Henkel for software support, M. Beyss for quasicrystal growth, and the Deutsche Forschungsgemeinschaft for financial support under Grant No. UR 51/3-1.
${ }^{1}$ For an overview, see New Horizons in Quasicrystals: Research and Applications, edited by A. I. Goldman, D. J. Sordelet, P. A. Thiel, and J. M. Dubois (World Scientific, Singapore, 1997).

${ }^{2}$ T. M. Schaub, D. E. Bürgler, H.-J. Güntherodt, and J. B. Suck, Phys. Rev. Lett. 73, 1255 (1994); Z. Phys. B 96, 93 (1994).

${ }^{3}$ M. Gierer, M. A. Van Hove, A. I. Goldman, Z. Shen, S.-L. Chang, C. J. Jenks, J. W. Anderegg, C.-M. Zhang, and P. A. Thiel, Phys. Rev. Lett. 78, 467 (1997); M. Gierer, M. A. Van Hove, A. I. Goldman, Z. Shen, S.-L. Chang, P. J. Pinhero, C. J. Jenks, J. W. Anderegg, C.-M. Zhang, and P. A. Thiel, Phys. Rev. B 57, 7628 (1998).

${ }^{4}$ Z. Shen, C. J. Jenks, J. Anderegg, D. W. Delaney, T. A. Lograsso, P. A. Thiel, and A. I. Goldman, Phys. Rev. Lett. 78, 1050 (1997).

${ }^{5}$ D. Naumović, P. Aebi, L. Schlapbach, and C. Beeli, in New Horizons in Quasicrystals: Research and Applications (Ref. 1), p. 86.

${ }^{6}$ A. I. Goldman and P. A. Thiel, in Quasicrystals: The State of the Art, edited by P. Steinhardt and D. Divincenzo (World Scientific, Singapore, 1998).

${ }^{7}$ Th. M. Schaub, D. E. Bürgler, H.-J. Güntherodt, J. B. Suck, and M. Audier, Appl. Phys. A: Mater. Sci. Process. 61, 491 (1995).

${ }^{8}$ C. J. Jenks, D. W. Delaney, T. E. Bloomer, S.-L. Chang, T. A. Lograsso, Y. Shen, C.-M. Zhang, and P. A. Thiel, Appl. Surf. Sci. 103, 485 (1996).

${ }^{9}$ S. Suzuki, Y. Waseda, N. Tamura, and K. Urban, Scr. Mater. 35, 891 (1996).

${ }^{10}$ Z. Shen, M. J. Kramer, C. J. Jenks, A. I. Goldman, T. Lograsso, D. Delamey, M. Heinzig, W. Raberg, and P. A. Thiel, Phys. Rev. B 58, 9961 (1998).

${ }^{11}$ D. Naumović, P. Aebi, C. Beeli, and L. Schlapbach, Surf. Sci. (to be published).

${ }^{12}$ B. Bolliger, M. Erbudak, D. D. Vvendensky, M. Zurkirch, and A. R. Kortan, Phys. Rev. Lett. 80, 5369 (1998).

${ }^{13}$ J. Chevrier, G. Cappello, F. Comin, and J. P. Palmari, in New Horizons in Quasicrystals: Research and Applications (Ref. 1), p. 144.
${ }^{14} \mathrm{Ph}$. Ebert, M. Feuerbacher, N. Tamura, M. Wollgarten, and K. Urban, Phys. Rev. Lett. 77, 3827 (1996).

${ }^{15} \mathrm{Ph}$. Ebert, F. Yue, and K. Urban, Phys. Rev. B 57, 2821 (1998).

${ }^{16}$ S. Suzuki, Y. Waseda, and K. Urban, Mater. Trans., JIM 39, 314 (1998).

${ }^{17}$ D. Rouxel, M. Gavatz, P. Pigeat, B. Weber, and P. Plaindoux, in New Horizons in Quasicrystals: Research and Applications (Ref. 1), p. 173.

${ }^{18}$ B. Grushko, N. Tamura, M. Feuerbacher, M. Beyss, and M. Wollgarten (unpublished); B. Grushko, M. Yurechko, and N. Tamura, J. Alloys Compd. (to be published).

${ }^{19}$ T. Gödecke and R. Lück, Z. Metallkd. 86, 109 (1995).

${ }^{20}$ M. Audier, M. Durand-Charre, and M. de Boissieu, Philos. Mag. B 68, 607 (1993).

${ }^{21}$ L. E. Davis, N. C. MacDonald, P. W. Palmberg, G. E. Riach, and R. E. Weber, Handbook of Electron Spectroscopy: A Reference Book of Standard Data for Identification and Interpretation of Auger Electron Spectroscopy Data (Physical Electronics Division, Perkin-Elmer Corp., Eden Prairie, MN, 1976).

${ }^{22}$ R. E. Honig and D. A. Kramer, Vapor Pressure Curves of the Elements (RCA Laboratories, Princeton, 1968).

${ }^{23}$ Th. Zumkey, H. Mehrer, K. Freitag, M. Wollgarten, N. Tamura, and K. Urban, Phys. Rev. B 54, R6815 (1996).

${ }^{24}$ R. Blüher, P. Scharwaechter, W. Frank, and H. Kronmüller, Phys. Rev. Lett. 80, 1014 (1998).

${ }^{25}$ Binary Alloy Phase Diagrams, edited by T. B. Massalski (American Society for Metals, Metals Park, OH, 1987), Vol. 1, p. 149.

${ }^{26}$ D. Naumović, P. Aebi, L. Schlapbach, C. Beeli, T. A. Lograsso, and D. W. Delaney, in Proceedings of the 6th International Conference on Quasicrystals, edited by T. Fujiwara and S. Takeuchi (World Scientific, Singapore, 1998), p. 749.

${ }^{27}$ Z. Shen, P. J. Pinhero, T. A. Lograsso, D. W. Delaney, C. J. Jenks, and P. A. Thiel, Surf. Sci. Lett. 385, L923 (1997).

${ }^{28}$ J. Friedel and F. Denoyer, C. R. Acad. Sci., Ser. II: Mec., Phys., Chim., Sci. Terre Univers 305, 171 (1987).

${ }^{29}$ G. Trambly de Laissardière, D. Mayou, and D. Nguyen Manh, Europhys. Lett. 21, 25 (1993). 